\title{
Analysis of the Role of Antibody-dependent Cellular Cytotoxic Antibody Activity in Murine Neonatal Herpes Simplex Virus Infection with Antibodies to Synthetic Peptides of Glycoprotein D and Monoclonal Antibodies to Glycoprotein B
}

\author{
Steve Kohl, ${ }^{*}$ Natalie C. J. Strynadka, ${ }^{\ddagger}$ Robert S. Hodges, ${ }^{\star}$ and Lenore Pereira \\ ${ }^{*}$ Department of Pediatrics, School of Medicine and ${ }^{\S}$ Department of Stomatology, School of Dentistry, University of California, \\ San Francisco, San Francisco, California 94143; and the ${ }^{\ddagger}$ Department of Biochemistry and Medical Research Council \\ of Canada Group in Protein Structure and Function, University of Alberta, Edmonton, Alberta, Canada T6G 2H7
}

\begin{abstract}
The role of antibody in neonatal herpes simplex virus (HSV) infection remains controversial. A battery of well-characterized monoclonal antibodies to HSV glycoprotein B (gB), and polyclonal antibodies against synthetic peptides of predicted epitopes of HSV glycoprotein D (gD) were used to determine in vitro functional activity and association with protection against lethal infection in a murine model of neonatal HSV disease. Antiviral neutralization activity of HSV was not associated with antibody-dependent cellular cytotoxicity (ADCC) activity to HSV-infected cells in vitro. In a model of high dose challenge (104 PFU), protection was not afforded by any antibody alone, but was by antibody plus human mononuclear cells, and highly associated with ADCC functional activity ( $P$ $<0.001)$. In a low dose challenge model, neutralizing activity of antibody alone was associated with protection in vivo ( $P$ $<0.001)$. Of the nine neutralizing epitopes of $\mathrm{gD}$ in vitro, eight were predicted surface regions. Four of the five epitopic sites of gD (2-21, 267-276, 288-297, and 303-312) that were determined to be important targets of ADCC and in vivo protection were also predicted to be surface regions. The only exception was the antiserum to region 52-61 which was predicted to be buried and also showed these activities. ADCC as well as neutralizing antibody activity are important in protection against neonatal HSV infection. (J. Clin. Invest. 1990. 86:273-278.) Key words: herpes simplex • antibody-dependent cellular cytotoxicity
\end{abstract}

\section{Introduction}

Neonatal herpes simplex virus (HSV) ${ }^{1}$ infection remains a devastating illness with increasing incidence $(1,2)$. The immunologic defects which predispose the neonate to severe HSV infection continue to be defined (for review see references 3 , 4). One of the most controversial areas remains the role of antibody in protection against neonatal HSV infection, and in

Address reprint requests to Steve Kohl, M.D., Division of Pediatric Infectious Diseases, Department of Pediatrics, Room 6E9, San Francisco General Hospital, San Francisco, CA 94110.

Received for publication 11 December 1989.

1. Abbreviations used in this paper: $\mathrm{ADCC}$, antibody-dependent cellular cytotoxicity; gB, glycoprotein B; gC, glycoprotein C; gD, glycoprotein D; HSV, herpes simplex virus; MC, mononuclear cells.

J. Clin. Invest.

(c) The American Society for Clinical Investigation, Inc.

$0021-9738 / 90 / 07 / 0273 / 06 \$ 2.00$

Volume 86, July 1990, 273-278 particular, if protective, the functional activity most closely associated with protection. We have previously used a murine model of neonatal HSV infection to study the human and murine neonate's cellular response to infection (5-11). We have now used this model to examine the function of several batteries of well-characterized antibodies. These include murine monoclonal antibodies (MAb) to HSV-1 glycoprotein B (gB) and glycoprotein $\mathrm{C}(\mathrm{gC})$ and rabbit polyclonal antibodies to synthetic peptides representing various segments of HSV-1 glycoprotein $\mathrm{D}(\mathrm{gD})$. We have shown a close association between antibody-dependent cellular cytotoxicity (ADCC) antibody activity in vitro and protection in vivo in combination with human leukocytes in a high viral dose challenge model. In a low dose challenge model antiviral neutralizing activity assumes importance in the absence of exogenous leukocytes. We have also identified functionally important epitopic domains of $\mathrm{gD}$ as targets of $\mathrm{ADCC}$ and in vivo protection against infection.

\section{Methods}

Monoclonal antibodies and antibodies to synthetic peptides. The monoclonal antibodies to $\mathrm{HSV} \mathrm{gB}$ were produced against HSV-1 (F), HSV-2(g), or immunoaffinity purified HSV-1gB and characterized as previously reported in detail $(12,13)$. All the MAbs used were to continuous epitopes on HSV-1 gB except H126-5 and H157-1 (13).

Antibodies to synthetic peptides of HSV-1 $\mathrm{gD}$ were generated in rabbits to 10 different peptides of 10 -residue segments ( 9 peptides) and a 20-residue segment (1 peptide) conjugated with carrier protein keyhole limpet hemocyanin as described in detail (14). The peptides were chosen for high probability of exposure on the $\mathrm{gD}$ molecule surface as predicted by algorithm Surfaceplot (14).

Virus. The virus used in ADCC, neutralization, and animal challenge experiments was HSV-1, strain HE previously isolated in the laboratory of Dr. André J. Nahmias (Emory University, Atlanta, GA) from a neonate with disseminated infection.

Neutralization assay. Neutralization assays were performed as previously reported (10) with HE strain (unless specified) by incubation of the dilution of antiserum or MAb to be tested with $\sim 50$ PFU of virus in minimal essential media (Hazleton Research Products, Denver, PA) supplemented with penicillin ( $50 \mathrm{U} / \mathrm{ml}$; Gibco Laboratories, Grand Island, NY), streptomycin ( $50 \mu \mathrm{g} / \mathrm{ml}$; Gibco Laboratories), L-glutamine (1.5\%; Gibco), and heat-inactivated FCS (10\%; Hazleton Research Products; supplemented minimal essential media, MEM) for 1 $h$ at room temperature. The resultant mixture was adsorbed on Chang liver cell monolayers for $1 \mathrm{~h}$, and overlayed with MEM plus $1.5 \%$ methylcellulose. Plaques were enumerated $3 \mathrm{~d}$ later after formalin fixing, with crystal violet staining. The neutralization titer was that resulting in $50 \%$ or greater reduction of PFU.

Human leukocyte preparation. All experiments using human blood were reviewed and approved by the appropriate institutional Committee for the Protection of Human Subjects. Heparinized $(10 \mathrm{U} / \mathrm{ml}$, sodium heparin; Elkins-Sinn, Inc., Cherry Hill, NJ) blood was processed by sequential dextran (Sigma Chemical Co., St. Louis, MO) 
sedimentation and Ficoll-Hypaque (Pharmacia Fine Chemicals, Piscataway, NJ) centrifugation as previously described (15). Mononuclear cells (MC) in the interface layer were washed three times in HBSS (Hazleton Research Products) and suspended in MEM.

Antibody-dependent cellular cytotoxicity assay. As previously reported in detail (16), ADCC was performed using Chang liver cells infected the day before use with HSV-1 (HE strain, MOI 1). These target cells were then labeled with radioactive sodium chromate (New England Nuclear, Boston, MA) and used in the cytotoxicity assay at a concentration of $2.5 \times 10^{4}$ cells $/ \mathrm{ml}$ (or $5 \times 10^{3}$ cells $/$ microtiter well; U-bottom well microtiter plates; Cooke, Alexander, VA). Effector cells were human MC purified as described above. Effector cells were used at an effector to target cell ratio of $30: 1\left(1.5 \times 10^{5} \mathrm{MC} /\right.$ microtiter well $)$. Antiserum or MAb was added to result in the desired final concentration, and the mixture (final volume $0.2 \mathrm{ml}$ ) was incubated for $18 \mathrm{~h}$ at $37^{\circ} \mathrm{C}$ in an atmosphere of $95 \%$ air and $5 \% \mathrm{CO}_{2}$.

To determine the amount of ${ }^{51} \mathrm{Cr}$ released from the target cells, 100 $\mu \mathrm{l}$ was aspirated from the top of each well without disturbing the cell button. To each well $100 \mu \mathrm{l}$ of $1 \mathrm{M} \mathrm{NaOH}$ was added and the total volume aspirated into a separate container. Each sample was counted in a gamma counter (model 4,000; Beckman Instruments Inc., Palo Alto, CA) for $1 \mathrm{~min}$. Chromium-51 release was calculated according to the following formula:

${ }^{\text {\%51 }} \mathrm{Cr}$ release $=\frac{2 A}{A+B} \times 100$,

where $A=$ counts per minute (cpm) in the top $100 \mu \mathrm{l}$, and $B=\mathrm{cpm}$ in the bottom $100 \mu$ to which $\mathrm{NaOH}$ was added. ADCC was calculated as:

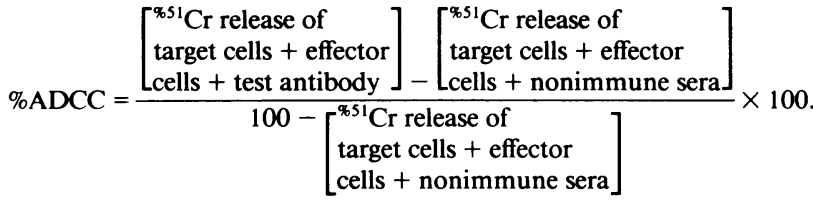

Each assay was performed in triplicate with SD of $<10 \%$. The spontaneous $18-\mathrm{h}{ }^{51} \mathrm{Cr}$ release of target cells in the presence of immune or nonimmune serum was $29.3 \pm 7.4 \%$. Sera or MAb mediating $10 \%$ or more ADCC activity are highly significant for anti-HSV ADCC activity (9).

Mouse protection model. As previously reported $(5,6)$ the murine protection model was performed using 1-wk-old $\mathrm{C} 57 \mathrm{Bl} / 6$ mice (Timco, Houston, TX), injected i.p. with $5 \times 10^{6}$ human MC suspended in MEM plus the desired concentration of serum or MAb in a final volume of $0.1 \mathrm{ml}$. The following day the animals were inoculated with $10^{4} \mathrm{PFU}$ of HSV-1 (HE strain, > $100 \mathrm{LD}_{50}$ for 1 -wk-old C57Bl/6 mouse) in a volume of $0.1 \mathrm{ml}$ unless otherwise specified. The animals were observed for survival for $21 \mathrm{~d}$. All animal experimentation was carried out in accordance with the National Institutes of Health animal care guidelines, and review and approval of the appropriate institutional animal care committee.

All animal experiments were performed in a blinded fashion in that the technician injecting the mice with various antibodies had no knowledge of which antibody or control he was using. The code was broken only after the animal survival rate was apparent.

Statistical analysis. Comparison of the significance of differences of antibody titers was performed by Student's two-tailed $t$ test. Comparison of survival of animals was tested by the $\chi^{2}$ analysis.

\section{Results}

Activity of rabbit antisera to HSV-I glycoprotein D synthetic peptides. In Table I, the neutralizing, ADCC, and in vivo protective activities of the anti-HSV-1 gD peptide antisera are summarized. All antisera tested displayed some neutralization activity against HSV-1 HE strain. All those antisera with neutralization activity of $1 / 200$ or greater also neutralized HSV-1
Table I. Activity of Rabbit Antisera to HSV Glycoprotein D Synthetic Peptides

\begin{tabular}{cccccc}
\hline & & & \multicolumn{2}{c}{ In vivo protection } \\
\cline { 5 - 6 } $\begin{array}{c}\text { Antisera to } \\
\text { synthetic peptide }\end{array}$ & Neutralization* $^{*}$ & ADCC & & + MC & Alone \\
\hline & & & $n \quad(\%)$ & $n$ \\
$2-21$ & $1: 200(1: 25)$ & $10^{-3}$ & $14 / 21(67)$ & $0 / 7$ \\
$52-61$ & $1: 50(\mathrm{ND})$ & $10^{-3}$ & $4 / 7(57)$ & $0 / 7$ \\
$267-276$ & $1: 100(1: 50)$ & $10^{-2}$ & $4 / 7(57)$ & $0 / 7$ \\
$288-297$ & $>1: 200(1: 25)$ & $10^{-3}$ & $5 / 7(71)$ & $0 / 7$ \\
$303-312$ & $1: 100(\mathrm{NN})$ & $10^{-3}$ & $6 / 7(86)$ & $0 / 7$ \\
$12-21$ & $>1: 200(1: 25)$ & 0 & $0 / 14(0)$ & $0 / 7$ \\
$63-72$ & $\mathrm{ND}(\mathrm{ND})$ & 0 & $0 / 7(0)$ & $0 / 7$ \\
$121-130$ & $1: 50(\mathrm{NN})$ & 0 & $0 / 21(0)$ & $0 / 7$ \\
$206-215$ & $1: 100(\mathrm{NN})$ & 0 & $0 / 7(0)$ & $0 / 7$ \\
$314-323$ & $1: 200(1: 25)$ & 0 & $0 / 7(0)$ & $0 / 7$ \\
& & & &
\end{tabular}

* Neutralization titer to HSV-1 HE strain. The numbers in parenthesis are titers to HSV-1, KOS strain as previously reported (14). $N D$, not performed; $N N$, nonneutralizing.

‡ ADCC titer to HSV-1-infected Chang liver cells.

$\S$ Protection in the presence of human mononuclear cells $\left(5 \times 10^{6}\right)$ mouse $+\mathrm{MC}$ ) or without cells (alone) of 7-d-old mice given $0.1 \mathrm{ml}$ i.p. of $10^{-2}$ dilution of antisera, challenged $1 \mathrm{~d}$ later with $10^{4} \mathrm{PFU}$ of HSV-1 i.p. Numbers are survivors divided by total challenged, and numbers in parenthesis are percent survival.

strain KOS. Those with titers of $1 / 100$ or less had no neutralizing activity against strain KOS with the sole exception of the antiserum to peptide 267-276 (Table I). There was a clear delineation between a group of antisera that mediated ADCC in vitro and those unable to do so. There was no difference in the neutralization titers against HSV-1 HE in the ADCC-active group (geometric mean titer 1/115) and the ADCC-inactive group (geometric mean titer $1 / 117, P>0.05$ by unpaired $t$ test). Each group contained antisera that failed to neutralize HSV-1 KOS strain (Table I).

Since the ADCC titers were relatively low compared to sera against whole virus (6), a relatively low dilution of antisera $\left(10^{-2}\right)$ was chosen to be used in the in vivo protection model. The antisera alone were completely ineffective in preventing lethal neonatal HSV infection (no survivors using any of the antisera, Table I). In sharp contrast, when the antisera was injected in combination with $5 \times 10^{6}$ human MC before viral challenge, there was obvious protective activity of five antisera (57-86\% survival). All animals receiving media or MC alone died (data not shown). As can be seen from Table I, all antisera able to mediate protection were in the group that mediated $A D C C$ in vitro. All antisera which were not protective in vivo in combination with MC could not mediate ADCC. The cumulative survival mediated by the ADCC-positive antisera in combination with MC $(33 / 49,67 \%)$ was highly significantly different $(P<0.001$, Chi-square test $)$ than that mediated by the ADCC-negative antisera $(0 / 56,0 \%)$.

To determine if there were protective effects of neutralizing activity in the absence of added MC that could not be discerned at high virus challenge doses $\left(10^{4} \mathrm{PFU}\right)$ but might be more obvious at lower doses $\left(10^{2}, 10^{3} \mathrm{PFU}\right)$ a series of experiments were performed using these lower viral challenge doses (Table II). Since there was no difference in survival of animals 
Table II. Protection by Rabbit Antisera to HSV Glycoprotein D Synthetic Peptides against a Small Challenge Dose of HSV in Mice

\begin{tabular}{|c|c|c|c|}
\hline \multicolumn{2}{|c|}{ Low neutralization ${ }^{*}$} & \multicolumn{2}{|c|}{ High neutralization ${ }^{*}$} \\
\hline $\begin{array}{c}\text { Antisera to } \\
\text { synthetic peptide }\end{array}$ & Survival' & $\begin{array}{c}\text { Antisera to } \\
\text { synthetic peptide }\end{array}$ & Survival ${ }^{6}$ \\
\hline & $n \quad$ (\%) & & $n \quad(\%)$ \\
\hline $52-61$ & $9 / 14(64)$ & $2-21$ & $12 / 14(86)$ \\
\hline $267-276$ & $8 / 14(57)$ & $12-21$ & $14 / 14(100)$ \\
\hline $303-312$ & $14 / 14(100)$ & $288-297$ & $14 / 14(100)$ \\
\hline $121-130$ & $13 / 14(93)$ & $314-323$ & $14 / 14(100)$ \\
\hline $206-215$ & $3 / 14(21)$ & & \\
\hline Total & $47 / 70$ (67) & & $54 / 56(96)$ \\
\hline
\end{tabular}

* Low neutralization sera mediated in vitro neutralization at titers of $1 / 50$ or $1 / 100$.

${ }^{\ddagger}$ High neutralization sera mediated in vitro neutralization at titers of $1 / 200$ or greater.

$\$$ Number of survivors divided by total number of challenged mice receiving $0.1 \mathrm{ml}$ i.p. of $10^{-2}$ dilution of antisera $1 \mathrm{~d}$ before i.p. inoculation with $10^{2} \mathrm{PFU}$ (one litter of seven animals) and $10^{3} \mathrm{PFU}$ (one litter of seven animals) of HSV in each group. Numbers in parentheses are percent survival.

receiving the $10^{2}$ or $10^{3}$ PFU challenge, the data are combined. There was a highly significant difference between survival mediated by antisera with neutralizing titers of $1 / 200$ or greater (96\%), compared to those with lower titers $(67 \%, P<0.001$, Chi-square test). Two of the four high neutralizing antisera had no ADCC activity (anti-12-21, anti-314-323). The mortality in mice receiving no antibody with the low challenge dose was $100 \%$ (0/20 survivors).

Thus it appears that in the neonatal murine model involving a high dose of virus, the participation of exogenous leukocyte effector cells, and the ADCC antisera activity is critical. In a low-dose challenge model in which exogenous leukocytes are

Table III. Activity of Murine Monoclonal Antibodies to HSV Glycoprotein B

\begin{tabular}{lcccc}
\hline & & & \multicolumn{2}{c}{ In vivo protection of $\mathrm{MAb}^{4}$} \\
\cline { 4 - 5 } Mab & Neutralization* & ADCC & + MC & Without MC \\
& & & $n \quad(\%)$ & $n$ \\
H 1394-1 & - & $10^{-2}$ & $7 / 7(100)$ & $0 / 8$ \\
H 1385-12 & - & $10^{-4}$ & $7 / 7(100)$ & $0 / 8$ \\
H 1396-7 & + & $10^{-2}$ & $4 / 7(57)$ & $0 / 8$ \\
H 126-5 & + & $10^{-3}$ & $0 / 7(0)$ & $0 / 8$ \\
H 336-1 & - & 0 & $0 / 7(0)$ & $0 / 8$ \\
H 1359-1 & - & 0 & $0 / 7(0)$ & $0 / 8$ \\
H 1399-6 & - & 0 & $0 / 7(0)$ & $0 / 8$ \\
H 157-1 & - & 0 & $0 / 7(0)$ & $0 / 8$
\end{tabular}

\footnotetext{
* Neutralization activity as previously published (13).

₹ ADCC titer to HSV-1-infected Chang liver cells.

${ }^{8}$ Protection in the presence or absence of human mononuclear cells $\left(5 \times 10^{6} /\right.$ mouse) of mice given $0.1 \mathrm{ml}$ of $10^{-2}$ dilution of MAb, challenged $1 \mathrm{~d}$ later with $10^{4} \mathrm{PFU}$ of HSV-1 i.p. Numbers are survivors divided by total challenged, and numbers in parentheses are percent survival.
}

not necessary, the neutralizing activity of the antisera are important, while the ADCC activity is not relevant.

Activity of murine monoclonal antibodies to $\mathrm{HSV}$ glycoprotein $B$. To confirm the importance of ADCC functional activity of antibodies in a high challenge dose protection model, a battery of MAb to HSV gB were used (Table III). As seen with the antisera to $\mathrm{gD}$ oligopeptides (Table I), no protection was mediated by a $10^{-2}$ dilution of MAb alone. In the presence of human MC, three of four MAb with ADCC activity mediated protection. MAb H126-5 was the sole exception and, of interest, had neutralizing activity and also was the only ADCC-active MAb against a discontinuous gB epitope. Two of the three protective MAb lacked neutralizing activity.

None of the MAb unable to mediate ADCC could mediate protection in combination with MC. The difference in cumulative survival mediated by ADCC-active MAb (18/28, 64.3\%) compared to those without ADCC activity $(0 / 28,0 \%)$ was highly significant $(P<0.0001$, Chi-square test). Thus as seen with antisera to $\mathrm{gD}$ synthetic peptides, the in vitro ADCC activity and not neutralization activity was associated with protection when combined with human MC in a high challenge dose model of neonatal HSV infection.

Activity of murine monoclonal antibodies to HSV glycoproteins $D$ and $C$. A small battery of MAb to glycoprotein D and $C$ were obtained to further substantiate our results (12, 17). These were screened using one dilution of $\operatorname{MAb}\left(10^{-2}\right)$ and those reactive in vitro in ADCC were used in the neonatal model of high viral challenge dose (Table IV). The MAb that mediated ADCC in vitro provided significant protection in vivo, as seen with the anti-gB MAb and anti-gD synthetic peptide antisera (Table IV). No protection was provided by $\mathrm{MAb}$ alone in these assays. A MAb to gB which failed to mediate ADCC (3S, kindly provided by Dr. Zwieg, NCI, 0\% ADCC) also failed to provide protection.

The four MAbs that mediated ADCC and were protective were all of the IgG2a subclass, as was the $3 \mathrm{~S}$ MAb. They were all neutralizing as previously reported $(12,17)$.

\section{Discussion}

The role of antibody regarding protection against neonatal HSV infection remains controversial. In animal studies, high

Table IV. Activity of Murine Monoclonal Antibodies to HSV Glycoprotein C and D

\begin{tabular}{lcccc}
\hline MAb* $^{*}$ & Glycoprotein & Neutralization & ADCC & In vivo protection" \\
\hline & & & & $n(\%)$ \\
HC1 & C & + & $34.0 \pm 6.1$ & $6 / 7(86)$ \\
19S & C & $1: 25$ & 13.0 & $6 / 8(75)$ \\
HD1 & D & + & $46.0 \pm 16.2$ & $8 / 14(57)$ \\
4S & D & $1: 25,600$ & $22.7 \pm 5.8$ & $18 / 24(75)$ \\
3S & B & $1: 800$ & $2.7 \pm 2.7$ & $1 / 8(12.5)$ \\
\hline
\end{tabular}

\footnotetext{
* MAb HCl and HDl were generated in the laboratory of Dr. Pereira as previously described (12), and $19 \mathrm{~S}$, $4 \mathrm{~S}$, and $3 \mathrm{~S}$ were generously provided by Dr. Martin Zweig, National Cancer Institute (17). ${ }^{\ddagger}$ Neutralizing activity was as previously reported $(12,17)$.

${ }^{8} \mathrm{ADCC}$ activity was tested at a $10^{-2}$ dilution in vitro.

"In vivo protection was tested in combination with $5 \times 10^{6} \mathrm{MC}$ using MAb at a $10^{-2}$ dilution.
} 
concentrations of antibody have been shown to protect against viral challenge when low doses of virus were used (18-23). Our data with low dose viral challenge (Table II) confirms that antibody alone can be protective in high concentration, and protection was generally associated with neutralization activity. This association, though highly statistically significant was not perfect in that several antisera with relatively low neutralization activity in vitro (e.g., anti-303-312, anti-121-130) were highly protective in vivo. It is possible that other functional activity as antibody complement neutralization or cytolysis, or viral opsonophagocytotic capacity may also be of importance.

In the human neonate the role of transplacental neutralization antibody has been particularly controversial (24-30). Our neonatal murine model of adoptive transfer involves an ADCC effector deficient host (31) as is the human neonate (32). In this model of uniformly lethal HSV infection due to large viral doses, protection could not be mediated by antibody alone, but required exogenous leukocytes as well implicating ADCC as a critical mechanism of protection (6). Cells with poor ADCC effector function in vitro, as those from patients with the leukocyte adhesion defect (LFA-1, Mac-1 defect), or from human neonates, also failed to mediate protection in this model $(5,33)$. We have now conclusively demonstrated that in this model, ADCC-active antibody (either $\mathrm{MAb}$ to $\mathrm{gB}, \mathrm{gC}, \mathrm{gD}$, or antisera to synthetic peptides of $\mathrm{gD}$ ) is highly associated with protection (Tables I, III, and IV). It is of interest that the single ADCC-active nonprotective MAb (H126-5, Table III) was to a discontinuous $\mathrm{gB}$ epitope.

In this high challenge dose model neutralization function was not associated with protection. These data supporting the role of ADCC as well as neutralizing antibody are in agreement with our recently published sero-epidemiologic study in human infants with neonatal HSV infection (34). Both ADCC and neutralization titers in the mothers or neonates were associated with the severity of infection in the neonate. High ADCC titers (neonatal titers over $10^{-3}$ ) were associated with the absence of disseminated disease. In these clinical situations the viral challenge dose is unknown.

In addition to implicating the functional mechanisms of protection induced by exogenous antibodies, the current studies help resolve the controversy surrounding the protective effects of anti-HSV MAbs. It has been shown that MAb reactive with infected cells but not virus could promote recovery from HSV infection (35). With some exceptions (36) neutralizing activity of MAbs has been shown to be unrelated to their in vivo protection in animal models $(35,37-40)$. When tested, protection correlated with ADCC function $(35,37,38)$. In the study of Rector et al. (41) one of the four MAbs that was protective in vivo failed to neutralize virus or mediate ADCC when using murine peritoneal effector cells. We have confirmed the lack of ADCC activity of this MAb in our in vitro ADCC assay using either murine or human effector cells. This $\mathrm{MAb}$ was not protective in our neonatal mouse system in combination with human MC (data not shown). Its protective activity in adult mice remains to be understood.

The results using $\mathrm{MAb}$ to $\mathrm{gB}, \mathrm{gC}$, and $\mathrm{gD}$ and antisera to specified peptides of $\mathrm{gD}$ (Table I) confirm the role of these three major HSV glycoproteins as important ADCC and in vivo targets of the immune system regarding antibody-mediated protection. These extend the results of previous studies using poly-specific antibodies $(42,43)$ and small batteries of $\operatorname{MAb}(35,37)$.

The data involving polyclonal sera to 10 different synthetic peptides of $\mathrm{gD}$ (Table I) allow for preliminary comments regarding ADCC epitopes. In the rabbit each of these peptides was immunogenic with appropriate carrier protein coupling (14). The peptide encompassing residues 2 to 21 was found to be comprised of at least two epitopes. One of these lies within the sequence 12 to 21 , which by itself elicits antibodies capable of neutralizing virions in the absence of complement (14). Peptide 2 to 21 retains the ability to generate complement-independent neutralizing antibody and in addition elicits the production of rabbit antibodies which neutralize virus very efficiently in the presence of complement (14). These results are compatible with those obtained by Cohen et al. (45), who demonstrated that rabbits immunized with synthetic peptide 8-23 developed HSV-1-neutralizing antibodies and that this determinant was the immunodominant determinant of HSV type $1 \mathrm{gD}$ (44-48). In addition, DeFreitas et al. (44) have shown that human $\mathrm{T}$ lymphocyte response in vitro was localized to a 16-residue region in the $\mathrm{NH}_{2}$-terminal sequence of 1-23 and that the synthetic peptide 12-23 was nonstimulatory.

The results of this study demonstrate that the antisera to 2-21 neutralize in vitro, have ADCC activity and provide in vivo protection in the presence of antibody and human mononuclear cells. In contrast, the synthetic peptide 12-21 antiserum demonstrated neutralization activity in vitro but failed to elicit in vitro or in vivo ADCC antiviral activity (Table I). Thus, the epitope responsible for ADCC activity appears to require, like the $\mathrm{T}$ cell stimulatory activity and complementdependent neutralizing activity, the $\mathbf{N H}_{2}$-terminal region 1-12. Interestingly, complement-dependent neutralization activity and ADCC activity are not always elicited by the same epitope. For example, antiserum to peptide 267-276 showed ADCC activity (Table I), the strongest complement-independent neutralization activity and no complement dependent activity (14).

The sequence 52-61 was predicted to be a nonepitopic site for surface expression and antiserum to this synthetic peptide did not bind to HSV-1 virions (KOS strain) (14). However, this study showed that this same antiserum had neutralization activity with the HSV-1 HE strain (Table I), solid ADCC activity in vitro, and mediated in vivo protection. Clearly, most studies to date have concluded that the majority of potentially neutralizing, immunogenic regions on an antigen are exposed on the surface of the molecule $(49,50)$. However, there are several examples in the literature which implicate a buried region of an antigen can be immunogenic. For example, two linear sites in the VPI coat protein of poliovirus induced a significant (1:150-1:200) neutralizing response in rats and rabbits, even though these regions have been shown by $x$-ray crystallographic studies to be deeply buried in the interior of the virion $(51,52)$. Analogous results and conclusions were also found with the hemagglutinin protein of the influenza virus (53), and with the protein myohemerythrin (54). The ability of these buried peptides to induce an antiviral response must arise from their exposure during the immune response and underlines the importance of understanding the dynamics of the antigen/antibody binding mechanism at the molecular level. An alternate explanation for the activity of antibodies to 
peptide sequence $52-61$ of $\mathrm{gD}$ is that the prediction of it as a buried region may be erroneous.

Thus while various predictive algorithms will help in the identification of important viral epitopes, the final selection of vaccine candidates must rely on empiric testing in appropriate models. If provision of a vaccine to a high risk mother, or antisera to a high risk neonate is to be effective in preventing neonatal HSV infection, antigens which elicit functional ADCC as well as neutralizing activity must be used.

\section{Acknowledgments}

The fine technical assistance of Lian Sim Loo and wordprocessing assistance of Ariane Otto-Marcus are appreciated. We thank Dr. Martin Zweig (National Cancer Institute, Bethesda, MD) and Dr. John Oakes (University of Alabama, Mobile, AL) for their kind provision of monoclonal antibodies.

This work was supported by National Institutes of Health grants AI 23247 (to S. Kohl), HD 13021 (S. Kohl), DE 08275 (to L. Pereira), grants from the Medical Research Council of Canada (R. S. Hodges), and an Alberta Heritage Fund for Medical Research Studentship (N. J. Strynadka).

\section{References}

1. Sullivan-Bolyai, J., H. F. Hull, C. Wilson, and L. Corey. 1983. Neonatal herpes simplex virus infection in King County, Washington. Increasing incidence and epidemiologic correlates. JAMA (J. Am. Med. Assoc.) 350:3059-3062.

2. Nahmias, A. J., H. L. Keyserling, and G. M. Kerrick. 1983. Herpes simplex. In Infections of the Fetus and Newborn Infant. J. S. Remington and J. O. Klein, editors. W. B. Saunders, Philadelphia, PA. 636-678.

3. Kohl, S. 1984. The immune response of the neonate to herpes simplex virus infection. In Immunology of Herpes Simplex Virus Infection. B. T. Rouse and C. Lopez, editors. CRC Press Inc., Boca Raton, FL. 121-130.

4. Kohl, S. 1989. The neonatal human immune response to herpes simplex virus: a critical review. Pediatr. Infect. Dis. J. 8:67-74.

5. Kohl, S., L. S. Loo, and L. K. Pickering. 1981. Protection of neonatal mice against herpes simplex viral infection by human antibody and leukocytes from adult but not neonatal humans. J. Immunol. 127:1273-1275.

6. Kohl, S., and L. S. Loo. 1982. Protection of neonatal mice against herpes simplex virus infection. Probable in vivo antibody-dependent cullular-cytotoxicity. J. Immunol. 129:370-376.

7. Kohl, S., L. S. Loo, and S. B. Greenberg. 1982. Protection of newborn mice from a lethal herpes simplex virus infection by human interferon, antibody, and leukocytes. J. Immunol. 128:1107-1111.

8. Kohl, S., R. H. Bigelow, and L. S. Loo. 1984. Ontogeny of protection of neonatal mice from lethal herpes simplex virus infection by human leukocytes, antiviral antibody, and recombinant alpha-interferon. Pediatr. Res. 18:1164-1167.

9. Kohl, S., P. A. Cox, and L. S. Loo. 1987. Defective production of antibody to herpes simplex virus in neonates: defective production of $\mathrm{T}$ helper lymphokine and induction of suppression. J. Infect. Dis. 155:1179-1187.

10. Kohl, S., L. S. Loo, D. B. Drath, and P. Cox. 1989. Interleukin-2 protects neonatal mice from lethal herpes simplex virus infection: a macrophage-mediated, gamma interferon-induced mechanism. J. Infect. Dis. 159:239-247.

11. Kohl, S. 1990. Protection against murine neonatal herpes simplex virus infection by lymphokine-treated human leukocytes. J. Immunol. 144:307-312.

12. Pereira, L., D. V. Dondera, D. Gallo, V. Devlin, and J. D.
Woodie. 1982. Serological analysis of herpes simplex virus types 1 and 2 with monoclonal antibodies. Infect. Immunol. 35:363-367.

13. Chapsal, J. S., and L. Pereira. 1988. Characterization of epitopes on native and denatured forms of herpes simplex virus glycoprotein B. Virology. 164:427-434.

14. Strynadka, N. C. J., M. J. Redmond, J. M. R. Parker, D. C. Scraba, and R. S. Hodges. 1988. Use of synthetic peptides to map the antigenic determinants of glycoprotein D of herpes simplex virus. $J$. Virol. 62:3474-3483.

15. Oleske, J. M., R. B. Ashman, S. Kohl, S. L. Shore, S. E. Starr, R. Wood, and A. J. Nahmias. 1977. Human polymorphonuclear leukocytes as mediators of antibody-dependent cellular cytotoxicity to herpes simplex virus-infected cells. Clin. Exp. Immunol. 27:446-453.

16. Kohl, S., S. E. Starr, J. M. Oleske, S. L. Shore, R. B. Ashman, and A. J. Nahmias. 1977. Human monocyte-macrophage-mediated antibody-dependent cytotoxicity to herpes simplex virus infected cells. J. Immunol. 118:729-735.

17. Showalter, S. D., M. Zweig, and B. Hampan. 1981. Monoclonal antibodies to herpes simplex virus type 1 proteins, including the immediate-early protein 1CP4. Infect. Immun. 34:684-692.

18. Baron, S., M. G. Worthington, J. Williams, and J. W. Gaines. 1976. Post exposure serum prophylaxis of neonatal herpes simplex virus infection of mice. Nature (Lond.). 261:505-506.

19. Luyet, F., D. Samra, A. Soneji, and M. I. Marks. 1975. Passive immunization in experimental herpes virus hominis infection of newborn mice. Infect. Immun. 12:1258-1261.

20. Cho, C. T., and K. K. Feng. 1977. Interaction of adenine arabinoside and host defense factors in experimental infections due to herpes virus hominis. J. Infect. Dis. 135:468-472.

21. Strulovitch, C., M. I. Marks, A. Soneji, and S. Goldberg. 1979. Immunotherapy and drugs in neonatal disseminated herpes simplex virus type 2 infections: a mouse model. J. Antimicrob. Chemother. 5:437-446.

22. Georgiades, J. A., J. Montgomery, T. K. Hughes, D. Jensen, and S. Baron. 1982. Determinants of protection by human immune globulin against experimental herpes neonatorum. Proc. Soc. Exp. Biol. Med. 170:291-297.

23. Kohl, S., and L. S. Loo. 1984. The relative role of transplacental and milk immune transfer in protection against lethal neonatal herpes simplex virus infection in mice. J. Infect. Dis. 149:38-42.

24. Yaeger, A. S., A. M. Arvin, L. J. Urbani, and J. A. Kemp. 1980. Relationship of antibody to outcome in neonatal herpes simplex virus infections. Infect. Immun. 29:532-538.

25. Whitley, R. J., A. S. Nahmias, A. M. Visintine, C. L. Fleming, and C. A. Alford. 1980. The natural history of herpes simplex virus infection of mother and newborn. Pediatrics. 66:489-494.

26. Whitley, R. J., A. Yeager, P. Kartus, Y. Bryson, J. D. Connor, C. A. Alford, A. Nahmias, and S. J. Soong. 1983. Neonatal herpes simplex virus infection: follow-up evaluation of vidarabine therapy. Pediatrics. 72:778-785.

27. Sullender, S. M., J. L. Miller, L. L. Yasukawa, J. S. Bradley, S. B. Black, A. S. Yeager, and A. M. Arvin. 1987. Humoral and cellmediated immunity in neonates with herpes simplex virus infection. $J$. Infect. Dis. 155:28-37.

28. Prober, C. G., W. M. Sullender, L. L. Yasukawa, D. S. An, A. S. Yeager, and A. M. Arvin. 1987. Low risk of herpes simplex virus infection in neonates exposed to the virus at the time of vaginal delivery to mothers with recurrent genital herpes simplex virus infection. $N$. Engl. J. Med. 316:240-244.

29. Whitley, R. J., L. Corey, A. Arvin, F. D. Lakeman, C. V. Sumaya, P. F. Wright, L. M. Dunkle, R. W. Steele, S. J. Soong, A. J. Nahmias, C. A. Alford, D. A. Powell, and V. San Joaquin. 1988. Changing presentation of herpes simplex virus infection in neonates. $J$. Infect. Dis. 158:109-116.

30. Sullender, W. M., L. L. Yasukawa, M. Schwartz, L. Pereira, P. A. Hensleigh, C. G. Prober, and A. M. Arvin. 1988. Type-specific antibodies to herpes simplex virus type 2 (HSV-2) glycoprotein G in 
pregnant women, infants exposed to maternal HSV-2 infection at delivery, and infants with neonatal herpes. J. Infect. Dis. 157:164-171.

31. Kohl, S., and L. S. Loo. 1980. Ontogeny of murine cellular cytotoxicity to herpes simplex virus-infected cells. Infect. Immun. 30:847-840.

32. Kohl, S., L. S. Loo, and B. Gonick. 1984. Analysis in human neonates of defective antibody-dependent cellular cytotoxicity and natural killer cytotoxicity to herpes simplex virus-infected cells. J. Infect. Dis. 150:14-19.

33. Kohl, S., L. S. Loo, F. S. Schmalstieg, and D. C. Anderson. 1986. The genetic deficiency of leukocyte surface glycoprotein Mac-1, LFA-1, p150,95 in humans is associated with defective antibody-dependent cellular cytotoxicity in vitro and defective protection against herpes simplex virus infection in vivo. J. Immunol. 137:1688-1694.

34. Kohl, S., M. S. West, C. G. Prober, L. S. Loo, W. Sullender, and A. M. Arvin. 1989. Neonatal antibody-dependent cellular cytotoxicity antibody levels are associated with the clinical presentation of neonatal herpes simplex virus infection. J. Infect. Dis. 160:770-776.

35. Rector, J. T., R. N. Lausch, and J. E. Oakes. 1984. Identification of infected cell-specific monoclonal antibodies, and their role in host resistance to ocular herpes simplex virus type 1 infection. J. Gen. Virol. 65:657-666.

36. Dix, R. D., L. Pereira, and J. R. Baringer. 1981. Use of monoclonal antibody directed against herpes simplex virus glycoproteins to protect mice against acute virus-induced neurological disease. Infect. Immun. 34:192-199.

37. Balachandran, N., S. Bacchetti, and W. E. Rawls. 1982. Protection against lethal challenge of Balb/C mice by passive transfer of monoclonal antibodies to five glycoproteins of herpes simplex virus type 2. Infect. Immun. 37:1132-1137.

38. Kino, Y., T. Eto, N. Ohtomo, Y. Hayashi, M. Yamamoto, and R. Mori. 1985. Passive immunization of mice with monoclonal antibodies to glycoprotein $\mathrm{gB}$ of herpes simplex virus. Microbiol. Immunol. 29:143-149.

39. Kumel, G., H. C. Kaerner, M. Levine, C. H. Schroder, and J. Glorioso. 1985. Passive immune protection by herpes simplex virusspecific monoclonal antibodies and monoclonal antibody-resistant mutants altered in pathogenicity. J. Virol. 56:930-937.

40. Metcalf, J. F., S. Chatterjee, J. Koga, and R. S. Whitley. 1988. Protection against ocular disease by immunotherapy with monoclonal antibodies to herpes simplex virus glycoproteins. Intervirology. 29:39_ 49.

41. Rector, J. T., R. N. Lausch, and J. E. Oakes. 1982. Use of monoclonal antibodies for analysis of antibody-dependent immunity to ocular herpes simplex virus type 1 infection. Infect. Immun. 38:168-174.

42. Norrild, B., S. L. Shore, and A. J. Nahmias. 1979. Herpes simplex virus glycoproteins: participation of individual herpes simplex virus type 1 glycoprotein antigens in immunocytolysis and their corre- lation with previously identified glycopolypeptides. J. Virol. 32:741748.

43. Norrild, B., S. L. Shore, T. L. Cromeans, and A. J. Nahmias. 1980. Participation of three major glycoprotein antigens of herpes simplex virus type 1 early in the infectious cycle as determined by antibody-dependent cell-mediated cytotoxicity. Infect. Immun. 28:38-44.

44. DeFreitas, E. C., B. Dietzschold, and H. Kopravski. 1985. Human T-lymphocyte response in vitro to synthetic peptides of herpes simplex virus glycoprotein D. Proc. Natl. Acad. Sci., USA. 82:34253429.

45. Cohen, G. H., B. Dietzschold, M. Ponce de Leon, D. Long, E. Golub, A. Varrichia, L. Pereira, and R. J. Eisenberg. 1984. Localization and synthesis of an antigenic determinant of herpes simplex virus glycoprotein D that stimulates the production of neutralizing antibody. J. Virol. 49:102-108.

46. Dietzschold, B., R. Eisenberg, M. Ponce de Leon, E. Golub, F. Hudecz, A. Varrichio, and G. H. Cohen. 1984. Fine structure analysis of type-specific and type-common antigenic sites of herpes simplex virus glycoprotein D. J. Virol. 52:431-435.

47. Eisenberg, R. S., D. Long, M. Ponce de Leon, J. T. Matthews, P. G. Spear, M. G. Gibson, L. A. Lasky, P. Berman, E. Golub, and G. H. Cohen. 1985. Localization of epitopes of herpes simplex virus type 1 glycoprotein D. J. Virol. 53:634-644.

48. Weijer, W. J., J. W. Drijfhout, H. J. Geerligs, W. Bloemhoff, M. Feijlbrief, C. A. Bus, P. Hoogerhout, K. E. T. Kerling, T. Popken-Boer, K. Slopsema, J. B. Wilterdiuk, G. W. Welling, and S. Welling-Wester. 1988. Antibodies against synthetic peptides of herpes simplex virus type 1 glycoprotein $D$ and their capability to neutralize viral infectivity in vitro. J. Virol. 62:501-510.

49. Dyson, H. J., R. A. Lerner, and P. E. Wright. 1988. The physical basis for induction of protein-reactive antipeptide antibodies. Annu. Rev. Biophys. Biophys. Chem. 17:305-324.

50. Mariuzza, R. A., S. E. V. Phillips, and R. J. Poljak. 1987. The structural basis of antigen-antibody recognition. Annu. Rev. Biophys. Biophys. Chem. 16:139-159.

51. Chow, M., R. Yabrou, J. Bittle, J. Hogle, and D. Baltimore. 1985. Synthetic peptides from four separate regions of the poliovirus type 1 capsid protein VP1 induce neutralizing antibodies. Proc. Natl. Acad. Sci. USA. 82:910-914.

52. Hogle, J. M., M. Chow, and D. J. Filman. 1985. Three-dimensional structure of poliovirus at $2.9 \AA$ resolution. Nature (Lond.). 289:366-378.

53. Wilson, I. A., J. J. Skehel, and D. C. Wiley. 1981. Structure of the haemagglutinin membrane glycoprotein of influenza virus at $3 \AA$ resolution. Nature (Lond.). 289:366-378.

54. Getzoff, E. D., H. M. Geysen, S. J. Rodda, H. Alexander, J. A. Tainer, and R. A. Lerner. 1987. Mechanisms of antibody binding to a protein. Science (Wash. DC). 235:1191-1196. 